\title{
Infância e Microações Afirmativas em Contextos Significativos
}

\author{
Edmilson dos Santos Ferreira' \\ José Jairo Vieira'
} 'Universidade Federal do Rio de Janeiro (UFRJ), Rio de Janeiro/RJ - Brasil

RESUMO - Infância e Microações Afirmativas em Contextos Significativos. Este artigo tem por objetivo compreender como as crianças em idade pré-escolar constroem as suas relações étnico-raciais em uma creche universitária na cidade do Rio de Janeiro. Considera-se neste estudo três dimensões que emergiram da pesquisa: as microações afirmativas expressivas registram a autoexpressão das crianças; as microações afirmativas inclusivas consideram a participação das crianças negras e não negras em situação de inclusão e as microações afirmativas formativas tratam do desenvolvimento profissional docente. A pesquisa aponta para a importância das microações afirmativas no desenvolvimento de práticas sociais antirracistas e pretende contribuir para os estudos da infância e para educação das relações étnico-raciais.

Palavra-chave: Microações Afirmativas. Ações Afirmativas. Educação das Relações Étnico-Raciais. Infância. Creche Universitária.

\begin{abstract}
Childhood and Affirmative Micro Action in Significant Contexts. This article aims to understand how pre-school children build their ethnic-racial relationships in a university day care center in the city of Rio de Janeiro. This study considers three dimensions that emerged from the research: the expressive affirmative micro actions, register the children's self-expression; the inclusive affirmative micro actions consider the participation of black and non-black children in the situation of inclusion and formative affirmative micro actions, it is the professional development of teachers. Research points to the importance of affirmative micro actions in the development of anti-racist social practices and aims to contribute to childhood studies and the education of ethnic-racial relations.

Keywords: Affirmative Micro Actions. Affirmative Actions. Education of Ethnic-Racial Relations. Childhood. University Daycare.
\end{abstract}

Educação \& Realidade, Porto Alegre, v. 46, n. 3, el07778, 2021.

http://dx.doi.org/10.1590/2175-6236107778 
Infância e Microações Afirmativas em Contextos Significativos

\section{Introdução}

As crianças negras são sujeitos sócio-histórico-culturais, com sentimentos que envolvem tristeza e alegria, os quais a subjetividade e os seus desejos se organizam em processos de interação em contextos significativos (Ferreira; Vieira, Vieira, 2020). A partir das nossas primeiras leituras no campo da sociologia e da história da infância (Ariès, 1981; James; Prout, 1990; Qvortrup et al.,1994; Sarmento, 2001), desenhamos a base teórico-metodológica deste estudo ao elegermos as crianças como “[...] indivíduos sociais, sujeitos históricos, cidadãos e cidadãs produzidos na cultura e produtores de cultura. Cidadãos que têm direitos sociais, entre eles, direito à educação e à cultura” (Kramer, 2010, p. 21), ou seja, sujeitos da pesquisa com possibilidade de estabelecer novos olhares com as crianças, influenciados pela sociologia da infância, privilegiando a participação infantil e suas as relações étnico-raciais, em particular.

A infância, como categoria estrutural, possibilita a pesquisa com crianças sobre a produção de conhecimento estabelecida nas interações entre elas próprias em sua cultura de pares e nas suas relações com os adultos. Tal categoria se relaciona com outras - como criança e creche, mais especificamente, a creche universitária. Entretanto, esse estudo privilegiou o atendimento às crianças em idade pré-escolar em uma creche universitária do Rio de Janeiro. E, nesse cenário, configuram-se os contextos significativos que constituem a potência presente na rotina das crianças, a creche é uma categoria que representa a primeira etapa da educação básica, e a creche universitária está inserida no contexto do tripé universitário pautado no ensino, pesquisa e extensão, enquanto as crianças na faixa etária selecionada narram com muita eloquência e sinceridade os seus desejos, denunciam e criticam as questões étnico-raciais vivenciadas no contexto da educação infantil.

As crianças, portanto, compõem um coletivo, uma categoria social. Percebe-se, então, que as categorias creche e crianças possuem algo em comum: a passagem pela infância, ambas estão presentes em diferentes culturas geracionais. Em outras palavras, são categorias permanentes, pois expressam fases específicas do desenvolvimento infantil

Esta pesquisa sustenta-se, principalmente, ao valorizar a potência da voz e a ação social das crianças, mesmo diante das ausências, silêncios, gestos e atitudes que se observam em seu cotidiano. Considera-se também o olhar investigativo e a sutileza dessa escuta sensível para interpretar o universo infantil, a linguagem com que as crianças se posicionam para expressar o que pensam e sabem independentemente da escola. Estamos falando sobre uma abordagem baseada em ouvir, em vez de falar. Há uma fascinação que é aliada da dúvida e, juntamente com a investigação científica, exige flexibilidade para que as crianças usem todo o tempo necessário para revelarem seus desejos, questionamentos, e mais importante ainda, é criar situações para indagarem a si mesmas sobre as questões relevantes. 
Quando estamos com as crianças, não se deseja apenas que elas respondam às perguntas, mas pretende-se descobrir questões emblemáticas que deem contorno e profundidade às nossas indagações. Quivyr (1992) destaca que a pergunta como ponto de partida é o fio condutor fundamental da pesquisa e indica a singularidade da ação das crianças em meio às suas interações, tendo em mente que estas fazem parte de uma estrutura social complexa que as influencia, mas o conhecimento produzido nesse movimento interação-ação se configura como uma pesquisa intervenção, partindo do princípio de que “[...] as crianças, assim como os adultos, são participantes ativos na construção social da infância e na reprodução interpretativa de sua cultura compartilhada" (Corsaro, 2011, p. 19). Nesse sentido, as crianças negociam a sua participação de acordo com os seus interesses.

Pretende-se também interpretar a participação ativa das crianças quando revisitam as fotografias, seus desenhos e narrativas gravadas em vídeo filmados também por elas. Um aspecto central deste trabalho foi compreender como as crianças constroem suas relações étnicoraciais em contextos significativos.

O desenvolvimento da pesquisa reuniu as percepções das crianças, tendo uma creche universitária do sistema federal de ensino no Rio de Janeiro como cenário dos encontros com as crianças, esses encontros favoreceram a compreensão delicada de suas indagações e questionamentos diante de situações comoventes que ampliaram o sentimento de pertencimento ao grupo, no sentido de sentir-se acolhido e aceito para "[...] interpretar o que cada conjunto de narrativas revela sobre a relação do adulto com a criança no contexto onde se desenvolve a entrevista propriamente dita" (Pereira; Salgado; Souza, 2009, p. 1026). Essas narrativas deram visibilidade ao foco central desta pesquisa: o conhecimento mobilizado e produzido pelas crianças no processo de construção de suas relações étnico-raciais.

O trabalho investigativo de intervenção revela práticas sociais planejadas e implementadas com o propósito de ampliar a visibilidade das reflexões e ações protagonizadas pelas crianças. Os estudos de intervenção se aproximam da pesquisa-ação (Thiollent, 1986) e da unidade dialética reflexão-ação pautada na relação dialógica proposta por Paulo Freire (1981). A pesquisa-ação pressupõe uma implicação na relação entre o pesquisador, as crianças e os adultos envolvidos no campo empírico, socializando as experiências e conhecimento teóricometodológico da pesquisa.

Quanto às questões éticas da pesquisa, os nomes citados são fictícios, reduzidos ou abreviados e escolhidos pelas próprias crianças para preservar a identidade das crianças. Portanto, a abordagem teóricometodológica desta pesquisa assume a participação ativa das crianças ao longo das intervenções para a tessitura das microações afirmativas, considerando a infância como categoria social. As narrativas das crianças são repletas de sentidos, assim como as práticas singulares e histórias de vida trazidas com a sutileza da mediação das professoras e 
Infância e Microações Afirmativas em Contextos Significativos

suas famílias. Alderson (1995) defende que as crianças, na qualidade de sujeitos de direitos, autorizem a sua participação acerca dos objetivos e dinâmica da pesquisa.

Geertz (2008), ao investigar as relações balinesas, observou que muitas vezes as crianças são chamadas por seus nomes pessoais, dar nome aos pequenos traz algumas características extremamente significativas para a compreensão das ideias que as crianças produzem sobre a sua condição pessoal. De um modo geral, os nomes pessoais possuem elementos de uma identidade cultural simplesmente única. Os nomes pessoais traduzem uma experiência de construção da identidade cultural das crianças tanto no sentido de reafirmar o seu nome pessoal quanto no sentido de valorizar a ancestralidade na perspectiva das crianças.

O processo investigativo privilegiou a pesquisa com as crianças, e a temática branquitude esteve presente na narrativa das crianças a partir das negociações de sentidos, encontros e confrontos de ideias, sem excluir a possibilidade de desistir de participar dos encontros nas rodas de conversa e quando percebiam o envolvimento de outras crianças, já mudavam o posicionamento com aquele jeito manhoso tão peculiar entre os pequenos.

\section{Reflexões para Repensar a Branquitude}

Valter Silvério (2003), em seus estudos sobre racismo e discriminação racial, afirma que a branquitude está associada à experiência branca. Definindo-a como uma consciência silenciada que não consegue admitir a sua posição diante de conflitos raciais ou com dificuldades de relacionar-se com a experiência vivenciada pelos sujeitos negros, especialmente, diante das crianças pretas que tiveram os seus direitos violados ou sofreram com o preconceito.

Esta consciência silenciada ou experiência branca pode ser definida como 'uma forma sócio histórica de consciência' nascida das relações capitalistas e leis coloniais, hoje compreendida como 'relações emergentes entre grupos dominantes e subordinados' (Silvério, 2003, p. 241).

Em oposição a esta análise, os estudos de Edith Piza apresentam uma definição de branquitude mais precisa que contempla a compreensão dos desdobramentos das microações afirmativas desenvolvidas em parceria com as professoras e as crianças no campo de pesquisa. Portanto, “[...] branquitude é um movimento de reflexão a partir e para fora da própria experiência enquanto brancos. É o questionamento consciente do preconceito e da discriminação que pode levar a uma ação política antirracista” (Piza, 2005, p. 07).

A partir dessa definição proposta por Edith Piza, assumimos o conceito de branquitude como um estado de consciência crítica e disposição para negociar os privilégios atribuídos aos sujeitos brancos e a capacidade de reconhecer e combater as vantagens estrutural e estruturante da sociedade. Ao ressignificarmos essa experiência branca 
positiva, o conceito de branquidade assume a posição dos sujeitos que não estão dispostos a abrir mãos dos seus privilégios e vantagens em ralação a população negra.

Nessa perspectiva, as crianças observam suas professoras, familiares e seus próprios pares, percebem a sutileza do tratamento dado aos sujeitos pretos em diferentes contextos produzindo em suas culturas infantis, situações que podem ser consideradas racistas e seguindo a lógica do branqueamento, enquanto desejo de assumir as características da cultura dominante. Portanto, “[...] as crianças não percebem ou não distinguem o porquê de serem preteridas nas brincadeiras e na organização das atividades de livre escolha (Ferreira; Vieira; Vieira, 2017, p. 160). O impacto das manifestações simbólicas nas relações infantis leva as crianças a internalizarem representações preconceituosas, reafirmando o processo de socialização presente nas práticas cotidianas, o que consequentemente faz com que sejam expostas ao racismo.

Há um sentimento de recusa às características raciais entre as crianças negras, ampliando o desejo de pertencer e vivenciar a experiência branca e o fato de as professoras basearem-se na cor da pele ou nas características fenotípicas para diferenciar as crianças estabelecendo uma hierarquia racial e comentários feitos na presença dos pequeninos associados à cor preta em situações pejorativas podem constranger as crianças.

A ausência de atitudes positivas por parte dos professores e professoras sinaliza às crianças que elas não podem contar com a sua cooperação, visto que nada é feito e, a conivência por parte dos profissionais da educação banaliza a discriminação racial. Para Nilma Lino Gomes e Petronilha Silva, o desenvolvimento profissional dos professores se sobrepõe a outros conceitos como: aperfeiçoamento, formação em serviço e formação permanente. "Esse conceito possui uma conotação de crescimento e continuidade que supera a tradicional justaposição entre formação inicial e aperfeiçoamento de professores" (Gomes; Silva, 2002, p. 15). Nessa direção, esse processo formativo precisa ser aprofundado em defesa de uma educação antirracista.

\section{Microssociologia e Microações Afirmativas}

Nesse estudo, utiliza-se o conceito de microcosmo de Pierre Bourdieu e as contribuiçõos de Anthony Giddens para interpretar a institucionalização da microssociologia. Alice Casimiro Lopes (2006) nos chama a atenção sobre o risco em analisar as relações entre as instâncias macro e micro, seja pensando que haja uma certa autonomia ou, seja estabelecendo relações imediatas entre elas. Os discursos estruturalistas são característicos da modernidade, a autora não afirma que toda pesquisa de instâncias micro envolvendo sujeitos, ações e instituições assuma uma perspectiva teórica pós-estruturalista ou pós-moderna, mas reconhece que as concepções pós-estruturalistas valorizam os discursos das microinstâncias, que, por vezes, são desconsiderados pelos 
Infância e Microações Afirmativas em Contextos Significativos

discursos estruturalistas e modernos. Portanto, um aspecto relevante a ser destacado consiste no esforço teórico de entrelaçamento dialógico entre Bourdieu (2011) e Giddens (2001) para fundamentar o conceito de microações afirmativas. Toma-se por base o contexto macrossocial (agenda nacional e seus aspectos jurídicos), o contexto mesoestrutural (agenda acadêmica e institucional) e o contexto micro (ação com as crianças no âmbito das ações afirmativas).

Giddens (2001) também entende que as relações entre os planos micro e macro podem nos ajudar a enfrentar as desigualdades sociais. $\mathrm{O}$ autor define a microssociologia como o estudo das interações sociais presentes no cotidiano. Nesse sentido, a análise microssociológica concentra-se nas interações entre as crianças em pequenos grupos e nos aspectos políticos para a consolidação das microações afirmativas no cotidiano das crianças e suas infâncias.

Assim como os aspectos econômicos no universo da produção simbólica se configura como um microcosmo, enquanto campo político, ou seja, "[...] um pequeno mundo social relativamente autônomo no interior de um grande mundo social" (Bourdieu, 2011, p. 195). Esse microcosmo pode sofrer rupturas, influenciado pelo universo da economia ou pelo mundo da prática, do trabalho, da família, dos grupos religiosos e, evidentemente, pelo mundo das crianças, portanto, envolve as relações e microações que lhes são próprias e, relativamente autônomas em relação ao macrocosmo. Essa autonomia nos permite pensar o universo infantil e suas infâncias, em relação às especificidades das crianças negras e da educação infantil no contexto de uma creche universitária.

As microações afirmativas constituem-se sob o prisma da participação das crianças diante das demandas macro/micro que a instituição enfrenta no cotidiano escolar, privilegiando as ações com as crianças numa perspectiva contra hegemônica e favorecendo as dimensões subjetivas em relação a diversidade étnico-racial e as intervenções na prática pedagógica. As microações afirmativas estabelecem a interseção entre as interações e seus processos macro, partindo do princípio de que as relações micro/macro estão intimamente ligadas.

Nessa perspectiva, os estudos de Bourdieu possibilitam a análise das micropolíticas considerando a creche universitária como um campo de produção de conhecimento e saber acadêmico, portanto, a dimensão micropolítica constitui-se como a base das práticas cotidianas, ao potencializar a afirmação das diferenças étnico-raciais que se manifestam na escola e a partir das múltiplas linguagens - corporal, artística, pictória, oral, entre outras - que usamos para a interpretar os saberes e estabelecer parcerias com as crianças, inclusive favorecendo o debate nas reuniões pedagógicas. Esses encontros oportunizam a troca de ideias, a denúncia, evidenciam as desigualdades, discriminações e reivindicam o reconhecimento de uma política sociocultural e antirracista. Esse debate não é recente e continua sendo pautado nas lutas sociais pelo movimento negro e na escola, visibilizando os contextos 
sociais marginalizados pelo poder hegemônico, dando sentido à cultura de pares e ao conhecimento produzido pelas crianças.

Esta pesquisa teve como inspiração inicial a leitura da tese de Doutorado da Professora Regina de Fatima de Jesus (2004), seu estudo apresenta o conceito de microações afirmativas cotidianas em seus projetos, sustentado pelas narrativas das professoras investigadas e recorre ao conceito de conhecimento-emancipação proposto por Boaventura Sousa Santos (2002) para compartilhar essas narrativas, considerando que todo conhecimento é autoconhecimento.

A pesquisadora investigou as ações antirracistas das professoras e seu olhar sobre as crianças aproximando as suas reflexões da práxis de Paulo Freire em busca de um aprofundamento teórico-prático sobre uma lacuna presente na formação de professores, as relações étnico-raciais. Além do compromisso de acompanhar e desenvolver microações afirmativas que contribuam para modificar as relações de exclusão que marcam o cotidiano escolar, desde a infância (Jesus; Araújo; Silva, 2015).

André Souza e Luciana Silva refletiram a respeito das situações de discriminação sofridas na infância, como categoria social, e sobre o quanto essas ações afetam e transformam a nossas práticas e, concluíram que "[...] as microações afirmativas são estratégias de luta no cotidiano escolar, contra as ideologias racistas difundidas historicamente na sociedade brasileira" (Souza; Silva, 2018, p. 52). Nesse contexto, apresentamos a análise das narrativas das crianças e consideramos o conceito de microações afirmativas como uma categoria política e analítica para interpretar as práticas antirracistas na educação das relações étnico-raciais.

\section{Reflexões sobre as Políticas de Ação Afirmativa}

O debate sobre as ações afirmativas teve seu primeiro registro no Programa Nacional de Direitos Humanos de 1996, as demandas sociais foram consideradas como ações afirmativas para o acesso da população negra à universidade, às áreas de tecnologia de ponta e aos cursos profissionalizantes como resultado da Conferência Mundial sobre a promoção de igualdade social, que manifestou a preocupação das organizações internacionais em universalizar a educação em favor da equidade social (Ferreira; Vieira; Vieira, 2017).

As políticas de ação afirmativa se diferem, pela sua natureza, dessas emanadas do Estado e das diversas instituições e instâncias governamentais; daquelas políticas como as iniciativas de ações afirmativa criadas pela sociedade civil e com a força dos movimentos sociais (Vieira, 2003). Entretanto, há uma demanda crescente por práticas antirracistas em contextos significativos que atendam às especificidades das crianças e jovens em todas as etapas da educação básica, mesmo diante da implementação das Leis 10.639/03 e 11.645/08, que tornam obrigatória ensino da história e cultura africana, afro-brasileira e indígena. 
Infância e Microações Afirmativas em Contextos Significativos

E partir dessa dimensão prática se insere as microações afirmativas, incluindo as crianças e suas infâncias no contexto das práticas sociais, mas entendendo que implementar práticas antirracistas é um ato político, como afirma Paulo Freire. Portanto,

\begin{abstract}
As ações afirmativas podem ser entendidas como um conjunto de políticas, ações e orientações públicas ou privadas, de caráter compulsório, facultativo ou voluntário que têm como objetivo corrigir as desigualdades historicamente impostas a determinados grupos sociais e/ou étnico-raciais com um histórico comprovado de discriminação e exclusão. Elas possuem um caráter emergencial e transitório. Sua continuidade dependerá sempre de avaliação constante e da comprovada mudança do quadro de discriminação que as originou (Gomes, 2003, p. 222).
\end{abstract}

Incluímos nesse histórico de discriminação e exclusão, a narrativa entre o pesquisador e o Bob, uma de nossas crianças, sujeitos da pesquisa, que é emblemática para compreendermos a relevância dessas demandas:

(Pesquisador) Então, você é um garoto negro... E o Bob respondeu: Eu não sou negro, eu sou preto e marrom. Então se você é preto marrom, você é negro... continuou provocando: Mas eu não sou negro, porque eu sou só um garoto comum, preto e marrom... Então, você é um garoto negro?! Insistiu o pesquisador. Não, eu não gosto de ser negro! E ele seguiu brincando com um boneco do homem aranha pela sala (Vídeo - transcrição, 2017).

Na cena do menino comum, preto e marrom, refletimos sobre a cor da pele e observamos que a criança fez uma crítica profunda, ao não se reconhecer como uma criança negra. E fizemos a seguinte interpretação:

\begin{abstract}
Quando uma criança reclama que não quer ser negra, ela está nos dizendo que não quer o tratamento costumeiramente dado às pessoas pertencentes a este grupo racial. $\mathrm{O}$ que ela quer é não ser ironizada, receber apelidos, ser excluída das brincadeiras... Assim, melhor que chamá-la de 'moreninha' para disfarçar a sua negritude é cuidar para que ela receba atenção, carinho e estímulo para poder elaborar a sua identidade racial de modo positivo (Cavalleiro, 2001, p. 156).
\end{abstract}

O desafio das professoras e professores é direcionar às crianças negras falas explícitas contendo elogios a sua inteligência, estética e ao seu desenvolvimento. As falas explícitas assumem um posicionamento político nas microações afirmativas a respeito da família, da escola e do grupo social, estimulam as crianças a construírem a sua subjetividade e o sentimento de pertença racial.

A narrativa de Bob traduz o desejo das crianças por um conjunto de políticas e ações com o objetivo de minimizar as desigualdades no cotidiano da escola e que contemple as especificidades das crianças negras e de suas infâncias, essas ações denominam-se, microações afirmativas. 


\section{Microações Afirmativas e as Crianças: análise das narrativas}

Quando nos referimos à identidade da criança negra de forma afirmativa, nos referimos à construção da subjetividade enquanto forma de pensar, agir, de perceber-se e sentir a si, aos outros e ao mundo, produzindo conhecimento pelas diferenças sociais, culturais e políticas presentes em contextos significativos.

As cenas selecionadas contribuíram para a construção das dimensões de análise. O acervo pessoal de fotografias, gravações em áudio e vídeo registram as intervenções, assim como o protagonismo das crianças. Enquanto os vídeos expressaram os movimentos e revelaram a dinâmica envolvente das cenas que potencializaram a formulação de perguntas concernentes às situações observadas. Espera-se que as transcrições densas das imagens produzidas preservem o encantamento e a ousadia das interpretações das crianças. Para Maria Carmem Barbosa (2014, p. 243) “[...] as imagens feitas pelas crianças e as gravações em vídeos dos processos de investigação são instrumentos necessários para refletir sobre a prática pedagógica, divulgar experiências e sugerir diferentes possibilidade de intervenções".

A partir dos estudos de intervenção emergiram três dimensões das microações afirmativas considerando a perspectiva das crianças negras, não negras e em situação de inclusão:

Microações afirmativas expressivas - essa dimensão registra a autoexpressão das crianças, considerando suas necessidades de refletir sobre os seus sentimentos e emoções ao expressarem a sua criatividade para a construção de si mesmos. As atividades expressivas destacam os desenhos, fotografias e vídeos produzidos com/pelas crianças durante o processo de intervenção e estes revelam a imaginação das crianças, que surge de suas brincadeiras, desenhos e narrativas. Para Zoia Prestes (2016), a imaginação emerge na brincadeira e na ação das crianças com objetos que se tornam brinquedos ao atribuírem-lhes outros significados.

Os desenhos infantis expressam a percepção das crianças sobre as suas particularidades da vida cotidiana. O desenho é uma das mais importantes expressões simbólicas das crianças, considerando que ele precede a escrita da palavra e revela o que a comunicação oral não expressou, estimulando os pequenos a registrem sua diversidade étnicoracial. "Nesse sentido, o desenho infantil comunica, e fá-lo dado que as imagens são evocativas e referenciais de modo distinto e para além do que a linguagem verbal pode fazer" (Sarmento, 2011, p. 28-29). 
Figura 1 - Princesas Aliafá e Kiriku e a feiticeira

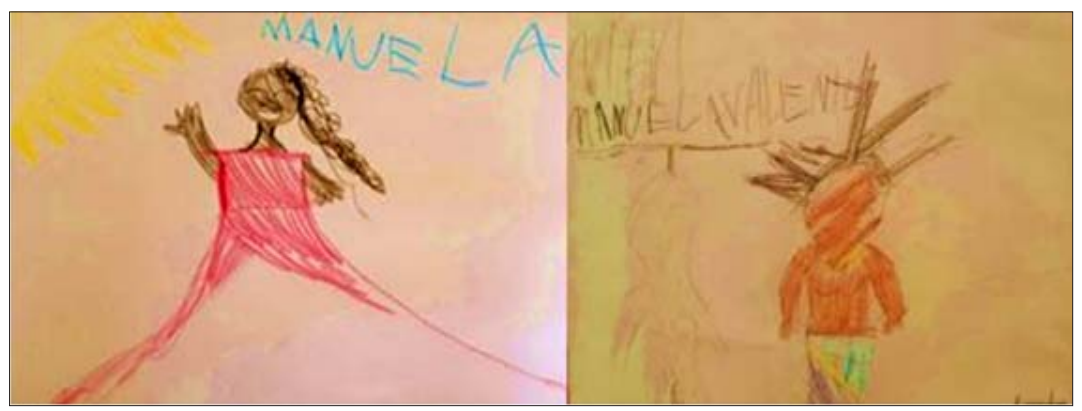

Fonte: Manu, 5 anos (2018).

Destaca-se na figura 1, os desenhos da Manu despois da história "Alafiá, a princesa guerreira", interpretada pela própria autora, Sinara Rubia (2019) protagonizou uma brilhante performance teatral para apresentar a saga de Aliafá, princesa do Reino do Adaomé. As crianças ficaram encantadas com a história de amor e aventura da princesa quilombola que combateu a escravidão. Os olhos atentos das crianças vibravam de emoção. A apresentação foi seguida por um rico debate sobre a temática étnico-racial em seguida foram disponibilizados papéis e lápis de cor para as crianças expressarem as suas percepções.

Manu também produziu o desenho de Kiriku e a feiticeira (Ocelot, 2016), inspirado na leitura de um dos livros mais procurados pelas crianças na sala de leitura. Elas ainda levavam os livros para casa no contexto do projeto literário, em que liam com as suas famílias. As crianças dramatizam a história, participaram ativamente da escrita do texto e na produção do cenário, confeccionaram as roupas colorindo os tecidos com tinta guache. Escolheram os personagens para contar a história do bebê africano que salvou o povo de sua aldeia e libertou a feiticeira de uma maldição.

Surpreendentemente, as crianças nos revelaram que "Karabá se transformou numa princesa no final, e o kiriku cresceu e casou com ela!” Disse a Manu. "Ele é um príncipe! Eu corro mais rápido que o Kiriku! (Bob, 5 anos). E ao olhar o desenho: "Ele tá pelado e fazendo xixi!", disse Manu rindo... Os desenhos de Manu, assim como a narrativa de Bob, revelam a alegria de se sentirem representados diante do protagonismo dos personagens negros.

Os desenhos são interpretados como produtos simbólicos, artefatos sociais e culturais da infância, ou seja, uma produção singular das crianças, cheia de significados e sentidos que expressam os seus valores culturais e a capacidade gráfica diferenciada presentes na infância, como categoria geracional, diante das possibilidades de interpretação no contexto da pesquisa.

Outra cena descrita - corpo em movimento - trata-se de uma prática observada na sala de movimento, assim chamam a sala com o piso coberto de tatames emborrachados destinada às práticas lúdicas 
com as professoras de dança e educação física. Em pares, as crianças desenharam o corpo com fita adesiva colorida com as cores disponíveis: azul, amarelo e verde, de acordo com a escolha das crianças; também levaram uma boneca branca para representar o corpo revelando que há poucas bonecas e bonecos negros na escola. Porém, foi possível perceber a preocupação das professoras ao longo da pesquisa em providenciar pelo menos uma boneca negra para dispor entre os brinquedos da sala.

A proposta consistia em movimentar o corpo, a dinâmica afetiva em que o corpo se movimenta nessa trama envolvente e permanece na posição enquanto outra criança a contornasse, a cena sucinta, a sensibilidade e os gestos ampliam a sua relação com seus pares. A dinâmica de expressão corporal fazia parte da sequência de movimentos que explorou os diferentes ritmos, inclusive a batida do funk.

Aliás, esse gênero musical tencionou as relações com as famílias, as críticas foram contornadas pela gestão e pelas professoras. Convém destacar que as famílias com capital cultural com inserção nas artes, especialmente, na música, acolheram e apoiaram as manifestações culturais produzidas pelas crianças. Essas tensões evidenciam as questões de classe, a segregação social e a religiosidade presentes no cotidiano escolar, ressaltando as demandas por microações afirmativas expressivas que fortaleçam a identidade das crianças e jovens negros e não negros oriundos das nossas favelas e periferias, conferindo ainda ao funk e outros ritmos periféricos o caráter transgressor e contestador das comunidades.

A dimensão das microações afirmativas expressivas incluem a relação espaço-temporal, amplitude dos gestos, o movimento, o ritmo e a interação com outro, com o espaço e o objeto, expressando os seus sentimentos. Para Le Breton (2009, p. 52), “[...] os sentimentos que vivenciamos, a maneira como repercutem e são expressos fisicamente em nós [...]. Eles inscrevem-se no rosto, no corpo, nos gestos, nas posturas etc.".

Essa experiência corporal faz parte do processo de socialização, os efeitos das cenas e os gestos das crianças as levaram a circular pela sala de movimento na tentativa de encontrar o movimento expressivo que se aproximasse da figura. O corpo é um fator de individualidade, portanto, as crianças tateando em suas marcações produzem um sentimento expressivo em relação a marca que diferencia, positivamente, os seus corpos negros dos outros e do mundo.

Microações afirmativas inclusivas - essa dimensão considera a participação das crianças negras e não negras em situação de inclusão. E a literatura infantil com crianças pretas protagonistas potencializa o encontro entre as crianças para dar contorno às relações de afeto, no sentido de afetar-se e afetar o outro pela sutileza dos cuidados, da atenção e pelo prazer de estarem juntos e encantados pela leitura de histórias. Abramowicz e Oliveira (2012) se esforçaram para construir a percepção acerca de uma criança e negra para pensar as relações entre raça, gênero e classe social. Nesse sentido, também temos aspectos positivos que podem ser relacionados a experiência das crianças, ou seja, 
Infância e Microações Afirmativas em Contextos Significativos

[...] as práticas vivenciadas na Educação Infantil podem possibilitar a criança e negra, a descoberta do seu pertencimento étnico-racial de uma maneira positiva, bem como podem auxiliar as não negras a se relacionarem bem com a diferença (Silva, 2015, p. 85).

As crianças apresentaram uma possibilidade de socialização numa perspectiva inclusiva, acolhendo e oportunizando situações que promovem e ampliam a participação das crianças numa perspectiva inclusiva. Essa dimensão também envolve a participação das famílias em encontros voluntários diante da complexa interação com as crianças em processo de inclusão. Uma especificidade do grupo observado foi a educação inclusiva, havia três crianças atendidas nessa perspectiva, e a literatura infantil preta favoreceu as interações entre as crianças. A interface entre a educação inclusiva e as relações étnico-raciais desenvolve o sentimento de solidariedade, cooperação e cuidados, mas não inclui o difícil desafio de socializar os brinquedos novos. Nesse caso, quando as crianças não estão em condições de negociar o empréstimo, o combinado do grupo é permanecer com o brinquedo guardado na mochila. Isso funcionou bem com o grupo; gradativamente, as crianças aprendem a socializar os brinquedos e incluir os demais amigos nas brincadeiras.

Essa abordagem tensiona a complexa interação que se estabelece no grupo. Se, por um lado, o coletivo torna-se mais sensível às questões inclusivas e isso favorece as crianças negras que saíram do foco das situações de discriminação, por outro, a possibilidade de discriminação assume outro contorno numa perspectiva inclusiva, socializar um brinquedo não é uma tarefa nada fácil na cultura de pares, gerando conflitos que precisam da mediação das professoras.

Contudo, a atenção das crianças durante a pesquisa foi direcionada aos encontros literários. Nos momentos de leitura, eram contadas histórias com crianças negras como protagonistas, especialmente aquelas que poderiam ser contadas também por meio de efeitos especiais, como os efeitos sonoros, a partir da percussão do próprio corpo com instrumentos ou brinquedos. Na atividade, havia, também, a presença de brinquedos cantados, os quais as mobilizam à sonoridade dos ritmos africanos e afro-brasileiros - a familiaridade com tais ritmos potencializa as práticas antirracistas. As microações afirmativas inclusivas incentivam a atenção com o outro e o respeito mútuo, favorecendo as intervenções através de atividades cooperativas e colaborativas, assim como quando as famílias compartilham o processo de inclusão negociando as relações de convivência.

As atividades inclusivas estimulam as crianças com a possibilidade de comunicação não verbal, através de instalações artísticas que oportunizam, de maneira lúdica e livre, a experiência sensível e criativa dos sujeitos, favorecendo os encontros coletivos e individuais.

Consequentemente, as professoras estão em um movimento constante para reduzir as desigualdades e a discriminação que se con- 
figurem no contexto escolar. Portanto, “[...] não podemos, contudo, é perder a visão processual e interminável da inclusão. Por mais 'inclusivas' que as instituições se tornem, haverá sempre a necessidade de um caminhar em direção à inclusão" (Santos, 2002, p. 117).

Microações afirmativas formativas - trata-se da formação de atitudes, a construção do respeito e de valores que estimulem o pertencimento étnico-racial seja através de um acervo bibliográfico (literatura infantil, músicas, vídeos), jogos e brincadeiras que despertem sensibilidade à temática. As professoras são mediadoras nesse processo, ao mesmo tempo que aprendem ou ampliam as suas reflexões pessoais com a participação das crianças. Os cursos de extensão e especialização comprometidos com a teoria e prática aprofundam o seu desenvolvimento profissional e ampliam os saberes docentes. A ancestralidade dialoga com a experiência dos mais velhos, e as famílias complementam essa tessitura que consiste, basicamente, em apresentar às crianças outros referenciais identitários positivos sobre o seu pertencimento étnicoracial.

Não obstante, as reflexões precisam envolver as famílias, através de um processo formativo que deve envolver as crianças, as famílias e suas professoras. Uma das atividades propostas pelas professoras foi a descrição das narrativas das crianças, como estratégia de promover o diálogo com as famílias sobre as questões raciais no contexto do projeto literário, através de um cartão colorido para comentar a literatura infantil negra escolhida pela própria criança:

\begin{abstract}
Percepção de raça aos olhos do Bob. Perguntamos para ele qual era a nossa cor, cor do cabelo e dos olhos. Ele nos vê na cor marrom. Os olhos da mãe são da cor preta e do pai marrom. Todos têm cabelo preto. Ele se vê na cor marrom também. Explicamos pra ele que nossa cor é uma mistura de raça, pois os avós são brancos e negros (Transcrição Família A - Anotações de campo, 2018).
\end{abstract}

Sem perceber, a família retoma as considerações de Oracy Nogueira (2006) sobre a ideologia miscigenacionista; percebe-se a demanda cada vez mais crescente por processos formativos para ampliarmos o debate numa perspectiva crítica. O desafio é traduzir as práticas pedagógicas acumulando ao longo do movimento de investigação-formação sobre como oferecer à comunidade escolar referenciais afirmativos positivos, especialmente, às crianças negras, prestigiando outras estéticas de origem africana ou afro-brasileira e que sejam, cuidadosamente, planejadas por pessoas da família ou pelas professoras com a participação das crianças (Jesus; Araújo; Silva, 2015).

Essa dimensão das microações afirmativas formativas está diretamente relacionada à ação cultural e política. A ação cultural constitui-se da construção teórica, considerando as práticas antirracistas. Os professores precisam vivenciar as práticas pedagógicas, ter acesso a referenciais teóricos consistentes em processos formativos que potencializem o seu desenvolvimento profissional. Especialmente, os professo- 
res que exercem o seu trabalho docente com crianças negras oriundas de classes populares têm a necessidade de pensar em contextos significativos a partir de microações afirmativas expressivas, inclusivas e formativas.

A ação libertadora propõe-se a romper com as práticas, atitudes e comportamentos racistas em movimentos reflexivos e formativos que potencializam a autoestima das crianças negras. Logo, as microações afirmativas revelam-se na intencionalidade das práticas educativas dos professores e professoras que promovem uma educação antirracista.

\section{Considerações Finais}

Silvério (2003, p. 60) reconhece que as discriminações raciais e o racismo, aparentemente, resultam em situações de exclusão e desigualdade social para os sujeitos e grupos que sofrem com essas "[...] práticas tanto no plano macro quanto no plano microssocial". O autor se questiona: “[...] como incorporar a diferença que faz diferença?” Não há uma resposta pronta e conclusiva diante de um país com tantas desigualdades sociais. Entretanto, as microações afirmativas orientam a construção de “[...] um projeto de dizer antirracista que se materialize no fazer cotidiano dos professores(as), técnicos(as) e crianças brancas, negras" (Motta; Paula, 2019, p. 16) e suas famílias. Nessa perspectiva, as relações sociais e as interações tencionam as identidades infantis e os modos de vida das crianças negras e não negras, “[...] ao mesmo tempo, a cultura aprofunda-se na mecânica da própria formação da identidade” (Hall, 1997, p. 6).

Ressalta-se a importância de implementar uma educação antirracista no cotidiano das crianças negras e não negras em busca de uma escola sem racismo, discriminação e preconceito. Se compararmos o quantitativo de crianças matriculadas no setor de educação infantil da creche universitária investigada, das 80 crianças matriculadas no ano letivo de 2017, observa-se, na fase exploratória da pesquisa, que apenas 17 crianças foram declaradas por suas famílias como pretas ou pardas, o equivalente a $21 \%$. Logo, se conclui que as crianças brancas representam 79\%. Nesse sentido, é possível afirmar que as desigualdades sociais e étnico-raciais ainda estão presentes nas práticas educativas escolares.

A obrigatoriedade do estudo da cultura e história das matrizes africanas, afro-brasileiras e indígenas desde a infância estão definidas pelas Leis 10.639/03 e 11.645/08, representam as instâncias macro e micro, isto é, as microações afirmativas indicam as relações imediatas entre elas. Para finalizar, esperamos que as microações afirmativas contribuam para produção de conhecimento sobre a infância e a educação básica.

Recebido em 23 de setembro de 2020 Aprovado em 29 de abril de 2021 


\section{Referências}

ABRAMOWICZ, Anete; OLIVEIRA, Fabiana. As Relaç̃es Étnico-Raciais e a Sociologia da Infância no Brasil: alguns aportes. In: BENTO, Maria Aparecida Silva (Org.). Educação Infantil, Igualdade Racial e Diversidade: aspectos políticos, jurídicos, conceituais. São Paulo: Centro de Estudos das Relações de Trabalho e Desigualdades - CEERT, 2012. P. 47-64.

ALDERSON, Priscilla. Listening to Children: children, ethics and social research. Barkingside: Barnardo's, 1995.

ARIÈS, Philippe. História Social da Criança e da Família. 2 ed. Rio de Janeiro: LTC, 1981.

BARBOSA, Maria Carmem Silveira. A Ética na Pesquisa Etnográfica com Crianças: primeiras problematizações. Práxis Educativa (Impresso), v. 9, p. 235-245, 2014.

BOURDIEU, Pierre. O Campo Político. Revista Brasileira de Ciência Política, n. 5. Brasília, jan./jul. 2011, p. 193-216.

BRASIL. Lei no 10.639 de 09 de janeiro de 2003. Inclui a obrigatoriedade da temática 'História e Cultura Afro-Brasileira' no currículo oficial da rede de ensino. Diário Oficial da União, Brasília, 2003.

BRASIL. Lei no ${ }^{\circ} 11.645$ de 10 de março de 2008. Inclui no currículo oficial da rede de ensino a obrigatoriedade da temática 'História e Cultura Afro-Brasileira e Indígena'. Diário Oficial da União, Brasília, 2008.

CAVALLEIRO, Eliane dos Santos (Org.). Racismo e Antirracismo na Educação: repensando nossa escola. São Paulo: Summus, 2001.

CORSARO, Willian. Sociologia da Infância. 2 ed. São Paulo: Artmed, 2011.

FERREIRA, Edmilson dos Santos. Infância e Microações Afirmativas em Contextos Significativos. 2019. 210 f. Tese (Doutorado em Educação) - Programa de Pós-graduação em Educação (PPGE), Universidade Federal do Rio de Janeiro, Rio de Janeiro, 2019.

FERREIRA, Edmilson dos Santos; VIEIRA, José Jairo; VIEIRA, Andreia Lopes. Habilidades Socioemocionais e Relações Étnico-Raciais no Contexto Escolar. Revista Cientifica UBM, Barra Mansa, ano XXII, v. 9, n. 37, p. 157-169, 2017.

FERREIRA, Edmilson dos Santos; VIEIRA, José Jairo; VIEIRA, Andreia Lopes. Relações étnico-raciais e saberes docentes na Escola de Educação Infantil da Universidade Federal do Rio de Janeiro. Revista Ibero-Americana de Estudos Educação, Araraquara, v. 15, n. 1, p. 236-252, jan./mar. 2020.

FREIRE, Paulo. Ação Cultural para a Liberdade. 5 ed. Rio de Janeiro: Paz e Terra, 1981.

GEERTZ, Clifford. 1926 - A interpretação das culturas. 1 ed. IS. Reimpr. Rio de Janeiro: LTC, 2008.

GIDDENS, Anthony. Sociologia. 6 ed. Lisboa: Polity Press; Associação com Blackwell Publishers Ltd., 2001.

GOMES, Nilma Lino. Educação, Identidade Negra e Formação de Professores/ As: um olhar sobre o corpo negro e o cabelo crespo. Educação e Pesquisa, São Paulo, v. 29, n. 1, p. 167-182, jan./jun. 2003.

GOMES, Nilma Lino; SILVA, Petronilha Beatriz Gonçalves. Experiências étnico-culturais para a formação de professores. Belo Horizonte: Autêntica, 2002.

Educação \& Realidade, Porto Alegre, v. 46, n. 3, e107778, 2021. 
Infância e Microações Afirmativas em Contextos Significativos

HALL, Stuart. A Centralidade da Cultura: notas sobre as revoluções de nosso tempo. Educação \& Realidade, Porto Alegre, v. 22, n. 2, p. 15-46, jul./dez. 1997.

JAMES, Allison; PROUT, Alan (Org.). Constructing and reconstructing childhood. Contemporary issues in the sociological study of childhood. Basingstoke: The Falmer Press, 1990. P. 248.

JESUS, Regina de Fátima de; ARAÚJO, Mairce da Silva; SILVA, Luciana Santiago da. Microações Afirmativas na Educação Infantil: diálogos com práticas pedagógicas. Revista Interinstitucional Artes de Educar, Rio de Janeiro, v. 1 n. 2, p. 212-228, jun./set. 2015.

JESUS, Regina de Fatima. Mulher negra alfabetizando: que palavra mundo ela ensina o outro a ler e escrever? 2004. 312 f. Tese (Doutorado) - Programa de Pósgraduação em Educação, Universidade Estadual de Campinas, Campinas, São Paulo, 2004.

KRAMER, Sonia. O que é básico na escola básica? Contribuições para o debate sobre o papel da escola na vida social e na cultura. In: KRAMER, Sonia; LEITE, Maria Isabel (Org.). Infância e produção cultural. Campinas: Papirus Editora, 2010. P. 11-24.

LE BRETON, David. A Sociologia do Corpo. Tradução de Sônia M.S. Fuhrmann. 3 ed. Petrópolis, RJ: Vozes, 2009.

LOPES, Alice Casimiro. Discursos nas Políticas de Currículo. Currículo sem Fronteiras, v. 6, n. 2, p. 33-52, jul./dez. 2006.

MOTTA, Flavia; PAULA, Claudemir de. Questões Raciais para Crianças: resistência e denúncia do não dito. Educação \& Realidade, Porto Alegre, v. 44, n. 2 , e88365, 2019.

NOGUEIRA, Oracy. Preconceito Racial de Marca e Preconceito Racial de Origem: sugestão de um quadro de referência para a interpretação do material sobre relações raciais no Brasil. Tempo Social, Revista de Sociologia da USP, v. 19, n. 1, 2006.

OCELOT, Michel. Kiriku e a Feiticeira. Rio de Janeiro: Viajante do tempo, 2016.

PEREIRA, Rita Marisa Ribes; SALGADO, Raquel Gonçalves; SOUZA, Solange Jobim. Pesquisador e Criança: dialogismo e alteridade na produção da infância contemporânea. Cadernos de Pesquisa, v. 39, n. 138, set./dez. 2009.

PIZA, Edith. Adolescência e racismo: uma breve reflexão. In: SIMPÓSIO INTERNACIONAL DO ADOLESCENTE, 1., 2005, São Paulo. Anais... São Paulo, 2005.

PRESTES, Zoia. A Brincadeira de Faz-de-Conta e a Infância. Trama Interdisciplinar, São Paulo, v. 7, n. 2, p. 28-39, maio/ago. 2016.

QUIVY, Raymond. et al. Manual de Investigação em Ciências Sociais. Lisboa: Gradiva, 1992.

QVORTRUP, Jens. et al. Childhood matters: social theory, practice and politics. Avebury: Aldershot, 1994.

RUBIA, Sinara. Alafiá. Rio de Janeiro: Nia Produções Literárias, 2019.

SANTOS, Monica Pereira dos. Educação Inclusiva: redefinindo a educação especial. Ponto de Vista, Florianópolis, n. 3/4, p. 103-118, 2002.

SARMENTO, Manuel Jacinto. Infância, Exclusão Social e Educação para a Cidadania Activa. Movimento, Revista da Faculdade de Educação da Universidade Federal Fluminense, Rio de Janeiro, n. 3, p. 53-74, maio 2001. 
SARMENTO, Manuel Jacinto. Conhecer a infância: os desenhos das crianças como produções simbólicas. In: MARTINS FILHO, Altino José; PRADO, Patrícia Dias (Org.). Das pesquisas com crianças à complexidade da infância. Campinas, SP: Autores Associados, 2011. P. 27- 60.

SILVA, Tarcia Regina da. Criança e negra: o direito à afirmação da identidade negra na Educação Infantil. Tese (Doutorado em Educação) - Centro de Educação da Universidade Federal da Paraíba, João Pessoa, 2015.

SILVÉRIO, Valter Roberto. Educação e Ações Afirmativas: entre a injustiça simbólica e a injustiça econômica. Brasília: Instituto Nacional de Estudos e Pesquisas Educacionais Anísio Teixeira, 2003.

SOUZA, Andre dos Santos; SILVA, Luciana Santiago da. Corporeidades negras e microações afirmativas: práticas antirracistas na educação infantil. In: FONTOURA, Helena Amaral. Pesquisas em processos formativos e desigualdades sociais. 1. ed. Niterói: Intertexto/FAPERJ, 2018. Vol. 1. P. 594.

THIOLLENT, Michel. Metodologia da Pesquisa-Ação. São Paulo: Cortez: Autores Associados, 1986.

VIEIRA, Andréa Lopes Costa. Políticas de educação, educação como política: observações sobre a ação afirmativa como estratégia política. In: SILVA, Petronilha Beatriz Gonçalves; SILVÉRIO, Valter Roberto. Educação e ações afirmativas: entre a injustiça simbólica e a injustiça econômica. Brasília: Instituto Nacional de Estudos e Pesquisas Educacionais Anísio Teixeira, 2003. P. 81-98.

Edmilson dos Santos Ferreira é Doutor em Educação pela Universidade Federal do Rio de Janeiro. Técnico em Assuntos Educacionais na Faculdade de Educação da UFRJ e Integrante do Ladecorgen-UFRJ.

ORCID: https://orcid.org/0000-0003-2561-7915

E-mail: baraoedmilson@gmail.com

José Jairo Vieira é Professor da Faculdade de Educação e dos Programa de Pós-Graduação em Educação (PPGE) e do Programa de Pós-Graduação em História Comparada (PPGHC) da UFRJ. Coordenador do Laboratório de Pesquisa em Desigualdade e Diversidade de Corpo, Raça e Gênero (LADECORGEN) da UFRJ.

ORCID: https://orcid.org/0000-0002-9395-5345

E-mail: diversidade.desigualdade.educa@gmail.com

Editora-responsável: Fabiana de Amorim Marcello

Este é um artigo de acesso aberto distribuído sob os termos de uma Licença Creative Commons Atribuição 4.0 Internacional. Disponível em: <http:// creativecommons.org/licenses/by/4.0>. 